\title{
Nano-crystalline Titanium(IV)Tungstomolybdate Cation Exchanger: Synthesis, Characterization and Ion Exchange Properties
}

\author{
Bezabih Kelta ${ }^{1}$, Isabel Diaz ${ }^{2,3}$, Álvaro Mayoral ${ }^{4}$, O.P. Yadav ${ }^{1}$, Abi M. Taddesse ${ }^{1, *}$ \\ ${ }^{1}$ Department of Chemistry, Haramaya University, Haramaya, Ethiopia \\ ${ }^{2}$ Instituto de Catálisis y Petroleoquímica, CSIC, c/Marie Curie 2, 28049 Madrid, Spain \\ ${ }^{3}$ Chemistry Department, Addis Ababa University, Addis Ababa, Ethiopia \\ ${ }^{4}$ Advanced Microscopy Laboratory (LMA), Nanoscience Institute of Aragon (INA), University of \\ Zaragoza, Zaragoza, Spain \\ * Corresponding author. Email: abi92003@yahoo.com; Mobile: +251 912 018750; Fax +251 25 \\ 5530325
}

\begin{abstract}
Nano-titanium(IV)tungstomolybdate cation exchanger has been synthesized via homogenous precipitation approach. Synthesis parameters have been optimized to get the highest ion exchange capacity (IEC). The as-synthesized nanoexchanger has been fully characterized by XRD, TEM, STEM/HAADF/EDS, FTIR and BET. The titanium(IV)molybdophosphate (TMP) behaves as bifunctional and strong acid cation exchanger with IEC of $2.41 \mathrm{meq} \cdot \mathrm{g}^{-1}$ for $\mathrm{Na}^{+}$ions. Very high distribution coefficient values for $\mathrm{Pb}^{2+}\left(K_{d}=10767 \mathrm{~mL} \cdot \mathrm{g}^{-1}\right)$ and $\mathrm{Cr}^{3+}\left(K_{d}=11800 \mathrm{~mL} \cdot \mathrm{g}^{-1}\right)$ ions indicate that the exchanger can be used to selectively adsorb $\mathrm{Pb}^{2+}$ and $\mathrm{Cr}^{3+}$ ions from the waste containing other metal ions. The exchanger has also showed a promising affinity towards a radionuclide $\mathrm{UO}_{2}{ }^{2+}\left(\mathrm{K}_{d}=7043 \mathrm{~mL} \cdot \mathrm{g}^{-1}\right.$ in $\left.0.1 \mathrm{M} \mathrm{DMSO}\right)$. The distribution study of the exchanger in different solvent systems showed promising separation potential of the exchanger towards metal ions of analytical interest from a given mixture for toxic heavy metal ions.
\end{abstract}

Key words: Cation exchanger, distribution coefficient, precipitation, ion exchange capacity, nanotitanium(IV) tungstomolybdate 


\section{Introduction}

Heavy metal pollution of water and soil is known to adversely affect the ecology causing health hazards in humans [1]. Unlike organic contaminants, heavy metals are not biodegradable and tend to accumulate in living organisms having toxic or carcinogenic effects [2]. A number of these toxic heavy metals have been discharged to the environment as industrial wastes, causing serious soil and water pollution [3]. Major contributors to environmental pollution with toxic metals are released from anthropogenic sources such as metal plating facilities, mining operations, fertilizer industries, tanneries, batteries, paper industries, pesticides, power regeneration and electronic industries [1].

Quantification of heavy metals in industrial effluents, various water and biological samples is important especially in the environment monitoring and assessment of occupational and environmental exposure to toxic metals [4]. Direct determination of trace metal ions in the samples of complex matrices still remains a difficult task because of inadequate sensitivity and selectivity of the methods employed and strong interference from the sample matrix. The matrix effects become more pronounced when the limitations of sophisticated analytical devices cannot be overlooked [5]. Thus, the best way is to separate the metal ions from the matrix constituents prior to their determination [6].

Several methods, such as chemical precipitation, electrolysis, membrane separation, and ion exchange are available to remove toxic metals from aqueous waste streams. Among the heavy metal removal processes, ion exchange process is very effective to remove various heavy metals and can be easily recovered and reused by regeneration operation. Thus, it is probably one of the most attractive processes and, consequently, the one commonly used in industry, because of its simple and efficient application as well as cost effectiveness [7].

Inorganic ion exchangers, due to their properties such as chemical and thermal stability, resistance to oxidation, unique selectivity to certain ions, have definite advantages over the well known and traditionally used organic resins [8]. Moreover, inorganic ion exchangers also have advantage in that they have a little tendency to swell in contact with water [9]. Currently, organic-inorganic hybrids or composite exchangers are being advocated for ion 
exchange applications owing to their advantages compared to pure organic or inorganic counter parts [10]. However, inorganic exchangers of better quality are required to fabricate novel composite exchangers. Further, different types of metal pollutants from chemical process industries necessitates finding new inorganic ion exchangers that have good ion exchange capacity, selectivity, thermal, radiation and chemical stabilities that are capable of removing toxic substances from waste water media of versatile nature [11].

Several studies show that mixed salts have better ion exchange properties as compared to single salt. These mixed salts have tetravalent metals such as $\mathrm{Ce}(\mathrm{IV}), \mathrm{Sn}(\mathrm{IV}), \mathrm{Ti}(\mathrm{IV})$ and $\mathrm{Zr}(\mathrm{IV})$ in combination with any two to four anions from $\mathrm{W}, \mathrm{P}, \mathrm{Mo}, \mathrm{Si}, \mathrm{V}, \mathrm{I}, \mathrm{Se}, \mathrm{As}$ and $\mathrm{Sb}$. $[5,6,12-15]$. Within the ever growing field of polyoxometalates, the tungstomolybdate system is relatively less studied; consideration of such systems in the ion exchange applications is therefore worthwhile. Ti(IV) based ion exchangers are known for their chemical and thermal stabilities compared to other tetravalent metals under identical conditions, so the synthesis of ion exchangers based on titanium is also worth considering [15]. To the best of our knowledge, no work has yet been reported on the preparation of titanium(IV)tungstomolybdate both in amorphous and nanocrystaline form. Nanocrytalline materials have been used as sorbent due to their improved intrinsic properties such as chemical activity and fine grain size compared with the classical substances [16-18]. Accordingly, the latest development in this field is potential applications of these nanomaterials for ion exchange applications $[10,19,20]$.

In the present study, nanotitanium(IV)tungstomolybdate has been produced via coprecipitation method using urea as a precipitating agent. The as-synthesized material has been characterized by X-ray diffraction (XRD), transmission electron microscope (TEM, STEM/HAADF/EDS), infrared spectroscopy (FTIR) and Brunauer-Emmett-Teller (BET) method and the ion exchange property of the material has been studied via batch equilibration technique. The exchanger demonstrated considerably high affinity towards analytically important metal ions such as $\mathrm{Pb}(\mathrm{II}), \mathrm{Cr}(\mathrm{III})$ and $\mathrm{U}(\mathrm{VI})$ in aqueous solution. 


\section{Experimental}

\subsection{Chemicals and Reagents}

The main reagents used for the synthesis of the nano-exchanger were titanium(IV) chloride, sodium tungstate and sodium molybdate all procured from SD fine chemicals, India. The following chemicals were also employed in the present work: manganese nitrate, copper nitrate and cadmium nitrate (SD fine chemicals, India); mercuric nitrate, lead nitrate, zinc nitrate, nickel nitrate, barium chloride, potassium chloride and sodium chloride (Blulux, India); urea and dimethyl sulfoxide (DMSO) (Abron chemicals, India); lithium chloride, calcium chloride, magnesium chloride, uranyl nitrate, chromium nitrate, potassium hydrogen phthalate, sodium hydroxide, phenolphthalein and disodium salts of EDTA (BDH, UK); hydrochloric acid and sulphuric acid (Blulux, India); nitric acid and N,N- dimethyl formamide (Breckland Scientific Supplies, UK); and formic acid (Fisher Scientific Company, USA). All the above chemicals and reagents were analytical grade and used with no further purification.

\subsection{Preparation of reagents}

Solution of $0.1 \mathrm{M}$ titanium(IV) chloride $\left(\mathrm{TiCl}_{4}\right)$ was prepared in $0.01 \mathrm{M} \mathrm{HCl}$ and $0.1 \mathrm{M}$ sodium tungstate dihydrate $\left(\mathrm{Na}_{2} \mathrm{WO}_{4} \cdot 2 \mathrm{H}_{2} \mathrm{O}\right)$ and $0.1 \mathrm{M}$ sodium molybdate dihydrate $\left(\mathrm{Na}_{2} \mathrm{MoO}_{4} \cdot 2 \mathrm{H}_{2} \mathrm{O}\right)$ solutions were prepared in deionized water. Urea solution, the precipitating agent, was prepared by dissolving $0.75 \mathrm{~g}$ urea crystals in $40 \mathrm{~mL}$ of deionized water.

\subsection{Optimization of synthesis parameters}

Before synthesis of the nano-titanium (IV) tungstomolybdate cation exchange material, the synthesis parameters such as concentrations of precursors, reactants molar ratio, amount of precipitating agent and reaction temperature were optimized based on the maximum ion exchange capacity obtained for a given parameter keeping the other synthesis parameters constant. 


\subsection{Synthesis of nano-titanium(IV) tungstomolybdate}

A $120 \mathrm{~mL}$ solution of $0.1 \mathrm{M}$ titanium tetrachloride in $0.01 \mathrm{M} \mathrm{HCl}, 0.1 \mathrm{M}$ sodium tungstate dihydrate and $0.1 \mathrm{M}$ sodium molybdate dihydrate in 4:1:1 mixing volume ratio was thoroughly mixed in $250 \mathrm{~mL}$ Erlenmeyer flask. Demineralized water $(80 \mathrm{~mL})$ containing $1.5 \mathrm{~g}$ of urea was then mixed with the above solution. The resultant milky white solution was then heated at $90^{\circ} \mathrm{C}$ for $1 \mathrm{~h}$ under continuous stirring. Precipitates of titanium(IV) tungstomolybdate thus formed were filtered out, washed twice with doubly distilled water to remove traces of chloride ions, and then dried at $40 \pm 1{ }^{\circ} \mathrm{C}$ for $24 \mathrm{~h}$. It was ground and calcined at various temperatures $\left(400^{\circ} \mathrm{C}, 500^{\circ} \mathrm{C}\right.$, and $\left.600^{\circ} \mathrm{C}\right)$ for $3 \mathrm{~h}$. The powder obtained was immersed into $1 \mathrm{M}$ nitric acid for $24 \mathrm{~h}$ with gentle stirring in order to transform the ion exchanger into its hydrogenated form. In order to determine the chemical and physical properties of the prepared samples, the one which showed the largest IEC for $\mathrm{Na}^{+}$ion was selected and characterized using physical and chemical characterization techniques [19, 21-23].

\subsection{Physical characterization techniques}

$\mathrm{pH}$ measurements were done using a single electrode digital $\mathrm{pH}$-meter (METTLER TOLEDO MP-220, Switzerland); The FTIR spectrum of the as-synthesized nanoexchanger was determined using the $\mathrm{KBr}$ disc method. The IR absorption pattern was recorded between 400 and $4000 \mathrm{~cm}^{-1}$ using SHIMADZU (1730, Japan) spectrometer. Four samples were prepared based on the optimized procedures (BK-1 to BK-4). Following this, the sample with high IEC, BK-4, was selected for further analysis. Accordingly, powder X-ray diffraction pattern was recorded with $\mathrm{X}^{\prime}$ Pert Pro PANalytical with CuK $\alpha$ radiation $(\lambda=1.5405 \AA)$. The data were registered with $2 \theta$ steps of $0.02^{\circ}$ and accumulation times of 20 s. Low magnification/particle size distribution TEM images of sample BK-4 were obtained using a transmission electron microscope (JEOL model JEM-2000 FX) at an accelerating voltage of $200 \mathrm{kV}$. STEM/HAADF analysis was performed in a spherical aberration corrected $\left(\mathrm{C}_{\mathrm{s}}\right.$-corrected) FEI XFEG Titan electron microscope operated at $300 \mathrm{kV}$. Both microscopes were equipped with an EDAX detector for spectroscopic analyses. Prior observations, the samples were dispersed in ethanol and placed onto a holey carbon copper microgrid. $\mathrm{N}_{2}$ adsorption isotherms were measured at $-196{ }^{\circ} \mathrm{C}(77 \mathrm{~K})$ on Micromeritics 
ASAP 2420 and the micropore surface area and volumes were calculated by the BrunauerEmmett-Teller (BET) method.

\subsection{Evaluation and chemical characterization of cation exchanger}

\subsubsection{Ion exchange capacity (IEC)}

The IEC of synthesized ion exchanger samples was determined by acid-base titration. The weighed sample of ion exchanger, in its $\mathrm{H}^{+}$form, was soaked in $50 \mathrm{~mL}$ of $1 \mathrm{M} \mathrm{NaCl}$ solution for $12 \mathrm{~h}$ with shaking at ambient temperature. The ion exchanged solution was titrated against $0.1 \mathrm{M} \mathrm{NaOH}$ solution to the phenolphthalein end point. The IEC was calculated using the equation below:

$$
\operatorname{IEC}(\mathrm{meq} / \mathrm{g})=\mathrm{V}_{\mathrm{NaOH}} \cdot \frac{\mathrm{C}_{\mathrm{NaOH}}}{\mathrm{W}_{\mathrm{d}}}
$$

Where $\mathrm{V}_{\mathrm{NaOH}}, \mathrm{C}_{\mathrm{NaOH}}$ and $\mathrm{W}_{\mathrm{d}}$ are the volume of $\mathrm{NaOH}$ in liter, the concentration of $\mathrm{NaOH}$ in milliequivalents per litre and the weight of the dry exchanger sample in $\mathrm{g}$, respectively [19].

\subsubsection{Effect of eluent concentration on IEC}

To determine the optimum concentration of the eluent for complete elution of $\mathrm{H}^{+}$ions, 0.5 $\mathrm{g}$ of ion exchanger was shaken for $12 \mathrm{~h}$ with $125 \mathrm{~mL}$ of $\mathrm{NaCl}$ solution with concentration ranging from $0.2 \mathrm{M}$ to $2 \mathrm{M}$ with step difference of $0.2 \mathrm{M}$. [6, 10].

\subsubsection{Effect of Contact time on IEC}

To evaluate the effect of contact time, $0.5 \mathrm{~g}$ of ion exchanger in $\mathrm{H}^{+}$form was shaken with $50 \mathrm{~mL}$ solution of $1 \mathrm{M} \mathrm{NaCl}$ solution and the amount of librated $\mathrm{H}^{+}$was determined by titration against $0.1 \mathrm{M} \mathrm{NaOH}$ solution after every 4, 8, 12, 16, 20, 24 and $48 \mathrm{~h}$, keeping other parameters constant. The time elapsed to achieve maximum IEC was taken as an optimum contact time for the batch equilibrium reactions [10]. 


\subsubsection{Effect of agitation speed on IEC}

To determine the optimum agitation speed, $0.5 \mathrm{~g}$ of ion exchanger in $\mathrm{H}^{+}$form was shaken with $50 \mathrm{~mL}$ of $1 \mathrm{M} \mathrm{NaCl}$ solution at 50,100,150, 200 and $250 \mathrm{rpm}$ for the optimum shaking time and the amount of librated $\mathrm{H}^{+}$was determined by titration against $0.1 \mathrm{M}$ $\mathrm{NaOH}$ solution, keeping other parameters constant. The rotor speed that resulted in maximum IEC was taken as an optimum agitation speed in the entire work.

\subsection{2. pH titration}

For the $\mathrm{pH}$ titrations, $0.5 \mathrm{~g}$ portions of the exchanger in $\mathrm{H}^{+}$form were placed in each of the eleven $250 \mathrm{~mL}$ conical flasks, followed by equimolar solutions of alkali metal chlorides and their hydroxides in different volume ratios, the final volume being $50 \mathrm{~mL}$ to maintain the ionic strength constant. The $\mathrm{pH}$ of the solution was recorded every $24 \mathrm{~h}$ until equilibrium was attained (which needed about 5 days) and $\mathrm{pH}$ at equilibrium was plotted against the milli-equivalents of $\mathrm{OH}^{-}$ions added [25,26].

\subsubsection{Ion exchange capacity for different metal ions}

Separation of metal ions was accomplished by batch equilibrium technique. Six equal parts of $0.5 \mathrm{~g}$ each of the exchanger in $\mathrm{H}^{+}$form was added into six different $250 \mathrm{ml}$ Erlenmeyer flasks. Then $50 \mathrm{ml}$ of $1 \mathrm{M}$ solutions of different alkali and alkaline earth metal chlorides (

$\mathrm{Li}^{+}, \mathrm{Na}^{+}, \mathrm{K}^{+}, \mathrm{Mg}^{2+}, \mathrm{Ba}^{2+}$ and $\mathrm{Ca}^{2+}$ ) were added separately to these flask and agitated on a shaker at $100 \mathrm{rpm}$ for $12 \mathrm{~h}$ and titrated against standard sodium hydroxide solution, separately. The ion exchange capacity for each metal ion was calculated as described in section 2.6.1 [26].

\subsubsection{Thermal stability}

The effect of thermal treatment of exchanger on its IEC was determined by heating $0.5 \mathrm{~g}$ of sample of the exchanger at different temperatures varying from $100^{\circ} \mathrm{C}$ to $800^{\circ} \mathrm{C}$ with a step of $100^{\circ} \mathrm{C}$ in muffle furnace for $1 \mathrm{~h}$. After cooling the sample at room temperature, $\mathrm{Na}^{+}$ 
ion exchange capacity was determined by the usual batch equilibrium method as described above $[26,27]$.

\subsubsection{Chemical stability}

To see the effect of different chemical environment on IEC of the exchanger, $0.5 \mathrm{~g}$ of ion exchanged material was equilibrated, separately, with $25 \mathrm{ml}$ each of different acids such as $\mathrm{HCl}, \mathrm{H}_{2} \mathrm{SO}_{4}, \mathrm{HNO}_{3}$, different bases such as $\mathrm{NaOH}, \mathrm{NH}_{4} \mathrm{OH}$, and organic solvents such as dimethyl sulfoxide (DMSO), acetone, ethanol and also dimineralized water (DMW) for 24 $\mathrm{h}$ at room temperature. The products were filtered and residue was washed with DMW to remove excess acid, base or organic solvent. The residue was then dried in oven at $40 \pm 1^{\circ} \mathrm{C}$ for 24. The ion exchange capacity of each of remaining material was determined by usual batch method $[10,26]$.

\subsubsection{Distribution coefficient studies}

Distribution coefficient $\left(\mathrm{K}_{\mathrm{d}}\right)$ was used to assess the overall ability of the material to remove the ion of interest under a set of conditions. A $0.3 \mathrm{~g}$ each of the exchanger in $\mathrm{H}^{+}$ form was mixed, separately, with $30 \mathrm{ml}$ of different metal ions $\left(\mathrm{Hg}^{2+}, \mathrm{Cr}^{2+}, \mathrm{Co}^{2+}, \mathrm{Pb}^{2+}\right.$, $\mathrm{Ni}^{2+}, \mathrm{Cd}^{2+}, \mathrm{Zn}^{2+}, \mathrm{Mn}^{2+}, \mathrm{Cu}^{2+}$ and $\mathrm{UO}_{2}{ }^{2+}$ ) in Erlenmeyer flasks and was shaken for $6 \mathrm{~h}$ at $25 \pm 2{ }^{\circ} \mathrm{C}$ to attain the equilibrium. The metal ion concentrations before and after the equilibrium were determined by EDTA titration. The distribution coefficients were calculated using equation (5) [24,26]:

$$
\begin{aligned}
& \mathbf{K}_{\mathbf{d}}=\frac{\frac{\text { Amount of metal ion in the exchanger phase }}{g \text { of exchanger }}}{\frac{\text { Amount of metal ion in the solution phase }}{m L \text { of solution }}} \\
& \text { Or } \\
& \mathbf{K}_{\mathbf{d}}=\frac{\boldsymbol{I}-\boldsymbol{F}}{\boldsymbol{F}} \frac{\boldsymbol{V}}{\boldsymbol{M}}\left(\boldsymbol{m} \boldsymbol{L} \cdot \boldsymbol{g}^{-\mathbf{1}}\right) \text { where: } \mathrm{F}=\text { final concentration of metal ion }\left(\mathrm{mgL}^{-1}\right) \\
& \mathrm{I}=\text { initial concentration of metal ion }\left(\mathrm{mgL}^{-1}\right) \\
& \mathrm{V}=\text { volume of the solution }(\mathrm{mL}) \\
& \mathrm{M}=\text { the dry mass of the cation exchanger }(\mathrm{g})
\end{aligned}
$$




\subsection{Statistical analysis}

The data was analyzed using SAS version 9.1 (2002-2003) to compare the ion exchange capacity of different samples and distribution coefficient of metal ions in different solvent systems.

\section{Results and Discussion}

\subsection{Synthesis of Nanotitanium(IV)Tungstomolybdate}

Nanotitanium(IV)tungstomolybdate was prepared via homogeneous precipitation technique using urea as a precipitating agent. The conditions used for the preparation have shown considerable effect on the ion exchange property of the as-synthesized material. The different factors affecting preparation conditions examined in this work were sodium tungstate concentration, amount of urea as a precipitating agent, mixing volume ratio of the reactants and precipitating temperature. The data generated were all in triplicates and average values were taken.

To determine the optimum concentration of sodium tungstate dihydrate, seven nanotitanium(IV) tungstomolybdate samples were prepared by varying the tungstate concentration and fixing the other parameters constant (Table 1). Among the different concentration studied, $0.1 \mathrm{M}$ sodium tungstate dihydrate exhibited relatively higher IEC and this was employed for the subsequent synthesis work. Sodium tungstate is the precursor for the anionic part where the replaceable $\mathrm{H}^{+}$attaches. Increasing the anionic part has positive result in lifting the IEC of exchangers to a certain extent. This is because as the anionic part inside the cation exchanger increases, there is also an increase in IEC. Further increase in the concentration of sodium tungstate; however, did not show commensurate increase in IEC of the exchanger, rather it tends to decrease. This could be attributed to the consumption of the $\mathrm{HCl}$ present in the preparation media. 
Table 1: Synthetic conditions optimized in the synthesis of Titanium(IV)tungstomolybdate x $\mathrm{Na}_{2} \mathrm{WO}_{4} \cdot 2 \mathrm{H}_{2} \mathrm{O}: 0.1 \mathrm{M} \mathrm{Na}_{2} \mathrm{MoO}_{4} \cdot 2 \mathrm{H}_{2} \mathrm{O}: 0.1 \mathrm{M} \mathrm{TiCl}{ }_{4}: 0.3 \mathrm{M}$ Urea

\begin{tabular}{|c|c|c|}
\hline $\mathrm{Na}_{2} \mathrm{WO}_{4} .2 \mathrm{H}_{2} \mathrm{O}(\mathrm{M})$ & Yield from $400 \mathrm{ml} \mathrm{sol} \mathrm{(g)}$ & IEC $\left(\right.$ meq $\left.^{-1}\right)$ \\
\hline 0.01 & $0.51 \pm 0.02$ & $0.76 \pm 0.02$ \\
\hline 0.10 & $0.56 \pm 0.03$ & $0.98 \pm 0.01$ \\
\hline 0.20 & $0.52 \pm 0.01$ & $0.70 \pm 0.03$ \\
\hline 0.40 & $0.57 \pm 0.02$ & $0.68 \pm 0.03$ \\
\hline 0.60 & $0.50 \pm 0.04$ & $0.66 \pm 0.04$ \\
\hline 0.80 & $0.56 \pm 0.04$ & $0.31 \pm 0.01$ \\
\hline 1.00 & $0.54 \pm 0.03$ & $0.02 \pm 0.02$ \\
\hline \multicolumn{3}{|c|}{$0.1 \mathrm{M} \mathrm{Na}_{2} \mathrm{WO}_{4} .2 \mathrm{H}_{2} \mathrm{O}: 0.1 \mathrm{M} \mathrm{Na}_{2} \mathrm{MoO}_{4} .2 \mathrm{H}_{2} \mathrm{O}: 0.1 \mathrm{M} \mathrm{TiCl}_{4}: \mathbf{x}$ Urea } \\
\hline Urea $(\mathbf{M})$ & Yield from $1 \mathrm{~L} \mathrm{sol}(\mathrm{g})$ & IEC $\left(\right.$ meq $\left.^{-1}\right)$ \\
\hline 0.0 & $2.30 \pm 0.04$ & $0.72 \pm 0.02$ \\
\hline 0.3 & $2.39 \pm 0.02$ & $0.98 \pm 0.02$ \\
\hline 0.6 & $2.34 \pm 0.01$ & $0.70 \pm 0.02$ \\
\hline 0.9 & $2.20 \pm 0.01$ & $0.60 \pm 0.02$ \\
\hline 1.3 & $2.12 \pm 0.10$ & $0.52 \pm 0.02$ \\
\hline \multicolumn{3}{|c|}{$0.1 \mathrm{Na}_{2} \mathrm{WO}_{4} .2 \mathrm{H}_{2} \mathrm{O}: 0.1 \mathrm{M} \mathrm{Na}_{2} \mathrm{MoO}_{4} .2 \mathrm{H}_{2} \mathrm{O}: 0.1 \mathrm{M} \mathrm{TiCl}_{4}: 0.3 \mathrm{M}$ Urea } \\
\hline $\begin{array}{c}\text { Precipitation } \\
\text { temperature }\left({ }^{\circ} \mathbf{C}\right)\end{array}$ & $\begin{array}{c}\text { Appearance of the products } \\
\text { after drying } \\
\text { at } 40 \pm 1^{\circ} \mathrm{C}\end{array}$ & IEC $\left(\right.$ meq $\left.\mathrm{g}^{-1}\right)$ \\
\hline 60 & white & $1.78 \pm 0.02$ \\
\hline 80 & white & $1.80 \pm 0.01$ \\
\hline 90 & bluish & $1.90 \pm 0.03$ \\
\hline 100 & light grey & $1.88 \pm 0.03$ \\
\hline 120 & light grey & $1.64 \pm 0.01$ \\
\hline
\end{tabular}


The amount of urea required to fabricate the exchanger with maximum IEC was also studied. Accordingly, five samples were prepared by varying the amount of urea (from 0 to $1.3 \mathrm{M})$. The amount of urea $(0.3 \mathrm{M})$ that resulted in highest IEC for $\mathrm{Na}^{+}$was taken as optimum and was used in the subsequent syntheses (Table 1). Further increase in the amount of urea beyond $0.3 \mathrm{M}$ did not provide better result in our case, rather the IEC continuously declined when the concentration of urea raised above $0.3 \mathrm{M}$. The decrease in IEC may be due to the presence of carbonate precipitate produced from the urea hydrolysis, which could contaminate the surface of the exchanger there by affecting the exchange capacity of the materials [28].

In order to determine the optimum mixing volume ratio of the precursors, seven samples with various mixing volume ratio were prepared keeping the other parameters constant (Table 1S). The mixing volume ratio of 4:4:1:1 comprising titanium tetrachloride, urea, sodium molybdate dihydrate, and sodium tungstate dihydrate in that order resulted in stable and large amount of precipitate. This was selected as an optimum mixing volume ratio for the subsequent steps.

The effect of temperature on the IEC of the exchanger materials was also assessed. This experiment was carried out by using the previously optimized synthetic conditions at various temperatures (Table 1). Maximum IEC (1.90 meq $\mathrm{g}^{-1}$ for $\mathrm{Na}+$ ions) was recorded for the sample that was precipitated at a temperature of $90 \pm 1{ }^{\circ} \mathrm{C}$. The IEC, initially, increases when the temperature is raised from $60^{\circ} \mathrm{C}$ to $90^{\circ} \mathrm{C}$. However, the IEC decreased beyond $90^{\circ} \mathrm{C}$ due to contamination by carbonate formed at higher temperatures. Furthermore, a sharp decrease in IEC is observed as the precipitation temperature is elevated to $120^{\circ} \mathrm{C}$. This may be attributed to the boiling of the synthesized ion exchanger at $120^{\circ} \mathrm{C}$. Our results conquer with the reports made previously [19, 29].

Finally, based on the optimum synthesis conditions displayed in Table 1, four samples of titanium(V)tungstomolybdate ion exchanger were prepared. Three of the samples were calcined at 400,500 and $600^{\circ} \mathrm{C}$ respectively, for $3 \mathrm{~h}$, leaving the other one uncalcined. Among these four samples, that one calcined at $600^{\circ} \mathrm{C}$ showed the maximum IEC $(2.41$ meq $\mathrm{g}^{-1}$ for $\mathrm{Na}^{+}$ions) (Table 2) and was selected for further investigation. 
Table 2: Physical appearance and ion exchange capacity of the as-synthesized exchanger and that calcined at varying temperature for $3 \mathrm{~h}$.

\begin{tabular}{llll}
\hline S. No. & $\begin{array}{l}\text { Calcination } \\
\text { temperature }\left({ }^{\circ} \mathrm{C}\right)\end{array}$ & $\begin{array}{l}\text { Appearance of the sample } \\
\text { after calcination }\end{array}$ & IEC $\left(\mathrm{meq}^{-1}\right)$ \\
\hline BK-1 & uncalcined & bluish & $1.23 \pm 0.01$ \\
BK-2 & 400 & smoke white & $1.87 \pm 0.01$ \\
BK-3 & 500 & pale yellow & $1.90 \pm 0.02$ \\
BK-4 & 600 & yellow & $2.41 \pm 0.03$ \\
\hline
\end{tabular}

\subsection{Characterization of titanium (V) tungstomolybdate ion exchanger}

\subsubsection{Fourier transform infrared spectroscopy (FTIR)}

The FTIR spectra of the as-synthesized cation exchanger titanium(IV) tungstomolybdate is presented in Figure 1. A broad relatively weak band in the region $3500-3000 \mathrm{~cm}^{-1}$ is attributed to interstitial water molecules and hydroxyl groups. The band is weak possibly because of loss of internal water molecules as the result of higher calcinations temperature used during the synthesis of the exchanger [11,30]. A sharp peak around $1623 \mathrm{~cm}^{-1}$ corresponds to the deformation/bending vibration of water molecules $(v \mathrm{H}-\mathrm{O}-\mathrm{H})$. A band at $\sim 1335 \mathrm{~cm}^{-1}$ may be due to deformation of vibration of metal hydroxyl groups [5]. The bands at around 827,619 and $418 \mathrm{~cm}^{-1}$ may be ascribed to M-O stretching bands. 


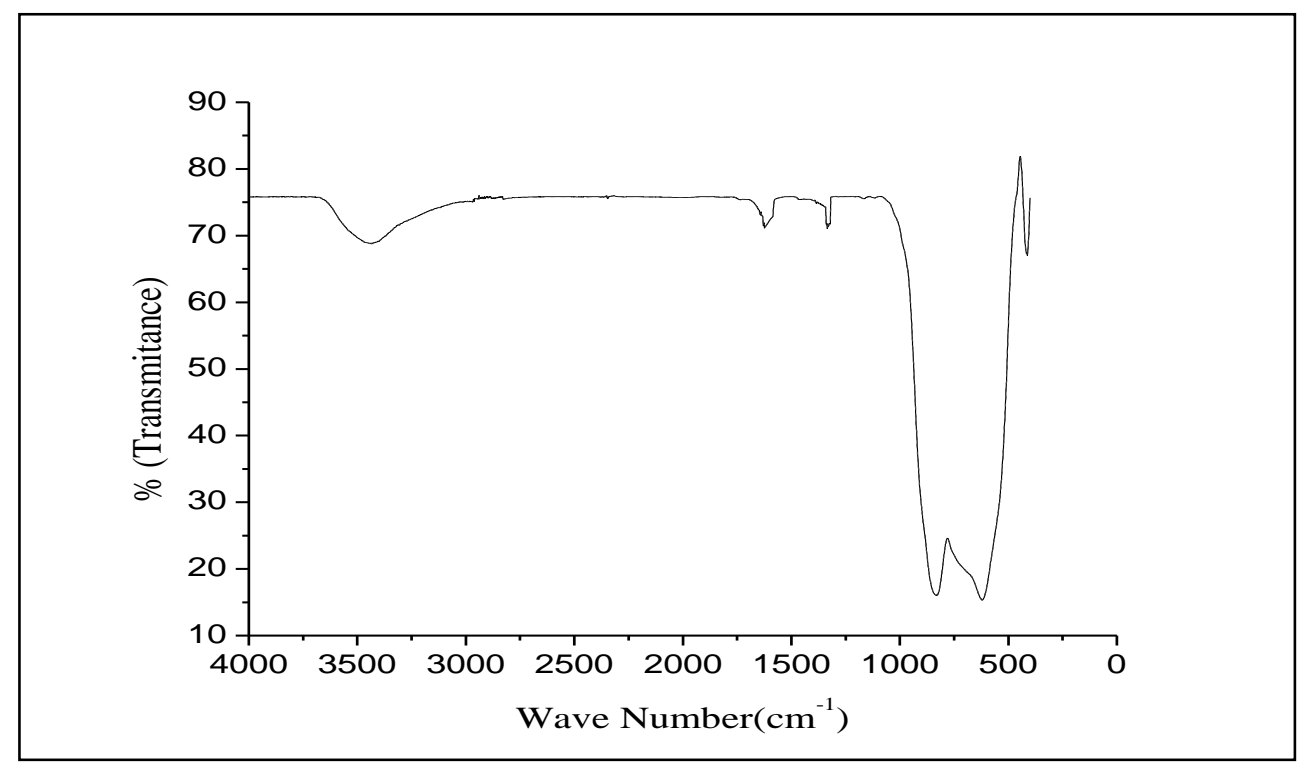

Figure 1. FTIR spectra of nanotitanium(IV) tungstomolybdate

\subsubsection{X-ray diffraction (XRD)}

The uncalcined sample shows no diffraction peaks revealing the amorphous nature of the exchanger (Figure S1). On the other hand, sharp and intense diffraction peaks are observed from the XRD patterns of the as-synthesized titanium(IV) tungstomolybdate samples calcined at the three different temperatures indicating that well crystalline structures are formed (Figure S1). This crystallinity was found to increase together with the calcination temperature, probably due to (Figure $\mathrm{S} 1$ ). the phase transformation of $\mathrm{TiO}_{2}$ from anatase to rutile. The same pattern of particle size-calcination temperature relationship was reported by $\mathrm{Li}$ and co-workers [31]. According to these scholars, the anatase nanoparticle size decreases slightly with the increase of substrate temperature until the transition temperature. However, increased particle size has been observed with increasing temperature once the transition temperature was surpassed. The XRD pattern of the assynthesized titanium (IV) tungstomolybdate exchanger (BK-4) is displayed in Figure 2. The presence of anatase is discarded in our sample, whereas the rutile phase of $\mathrm{TiO}_{2}(00-$ 034-0180) was predominant (45\%) with diffraction peaks at 2 theta $=27.6^{\circ}, 36.1^{\circ}, 41.3^{\circ}$, 
and $56.7^{\circ}$. Furthermore, tungstenmolybdeate could be identified with two different chemical ratios, being the major phase $\mathrm{W}_{0.71} \mathrm{M0}_{29} \mathrm{O}_{3}$ in the as-obtained nanoexchanger.

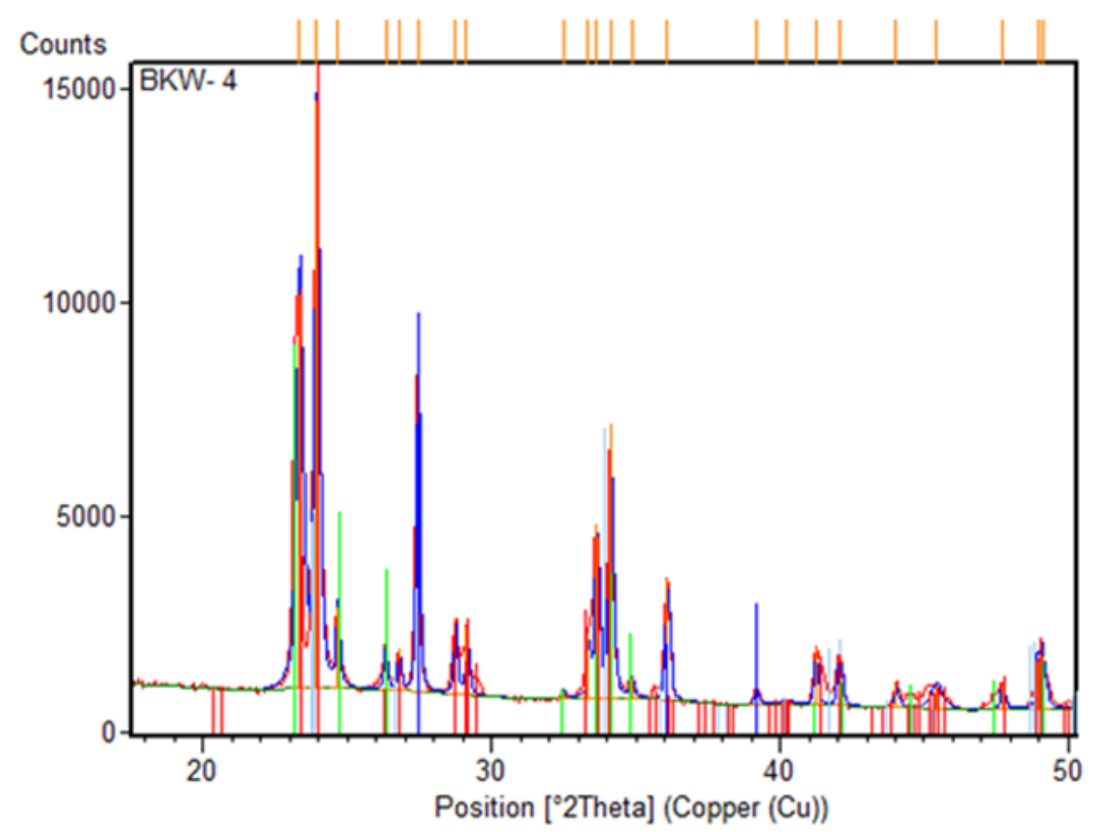

\begin{tabular}{|c|c|c|c|c|c|c|c|}
\hline & No. & Visible & Ref. Code & Compound Name & Chemical Formula & Score & SemiQuant [\%] \\
\hline \multirow[t]{3}{*}{ 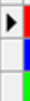 } & & $\checkmark$ & $01-076 \cdot 1279$ & Tungsten Molybd... & W.71 Mo.2903 & 62 & 64 \\
\hline & & $\checkmark$ & $00-034-0180$ & Rutile, syn & $\mathrm{TiO} 2$ & 45 & 17 \\
\hline & 3 & $\checkmark$ & $01-076 \cdot 1280$ & Tungsten Molybd... & W. 4 Mo.603 & 46 & 18 \\
\hline
\end{tabular}

Figure 2. $\mathrm{X}$ ray diffraction pattern of titanium (IV) tungstomolybdate calcined at $600^{\circ} \mathrm{C}$

\subsubsection{Surface Area}

The average specific surface area of the as-synthesized titanium(IV) tungstomolybdate cation exchange material calcined at $600^{\circ} \mathrm{C}$ (BK-4) was found to be $1.46 \mathrm{~m}^{2} / \mathrm{g}$ which indicates that the synthesized nanomaterial has relatively low specific surface area.

\subsubsection{Transmission Electron Microscopy studies.}

The homogeneity of the sample and the average particle size was initially investigated by systematic low magnification TEM coupled with EDS observations. Figure 3 shows a representative image in which regular spherical or oval shaped particles could be observed within the range of 50 to $100 \mathrm{~nm}$. Systematic EDS analyses (not shown) revealed that there were mainly $\mathrm{TiO}_{2}$ and $\mathrm{WO}_{3}$ particles, both showing presence of Mo up to $20 \%$ in the $\mathrm{WO}_{3}$ 
phase. Interestingly, higher resolution studies using spherical aberration $\left(\mathrm{C}_{\mathrm{s}}\right)$ corrected STEM/HAADF/EDS revealed that the particles rich in $\mathrm{TiO}_{2}$ contain both $\mathrm{W}$ and $\mathrm{Mo}$ in lower ratios, confirming that there is a mixture of the three metals. $\mathrm{C}_{\mathrm{s}}$-STEM-HAADF images in Figure 4 allow observing the highly ordered structure in the $\mathrm{TiO}_{2}$ particles, in which the brighter spots correspond to either $\mathrm{W}$ or Mo atoms randomly distributed in the structure. Figure $4 c$ shows the EDS spectrum of the image recorded in Figure $4 b$.
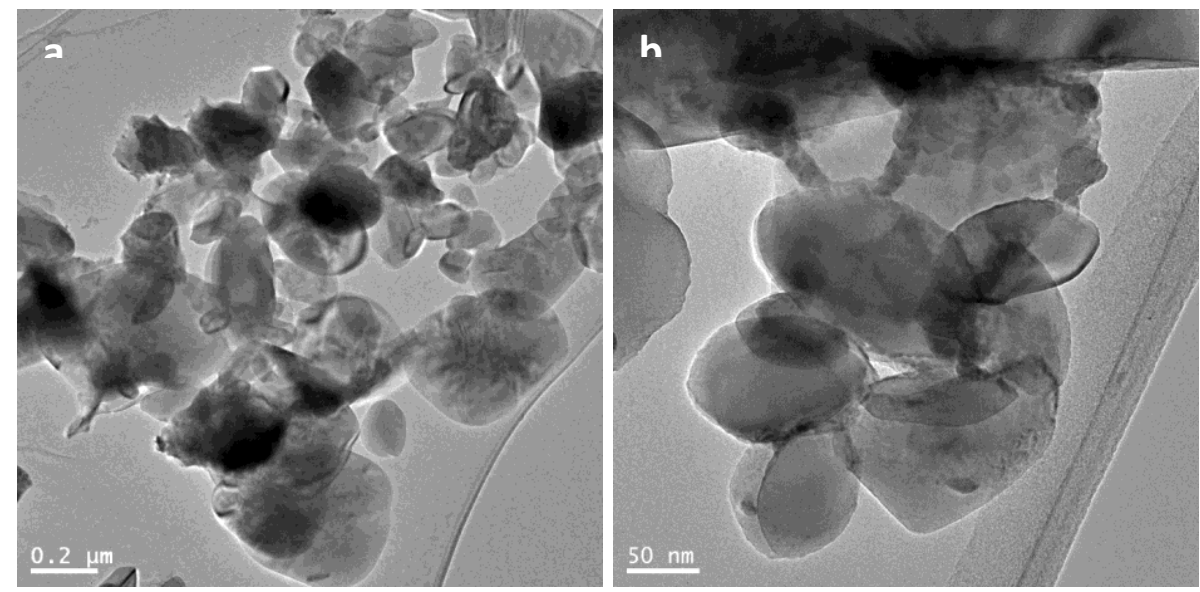

Figure 3. Low magnification TEM images of the BK-4 material at different magnifications.
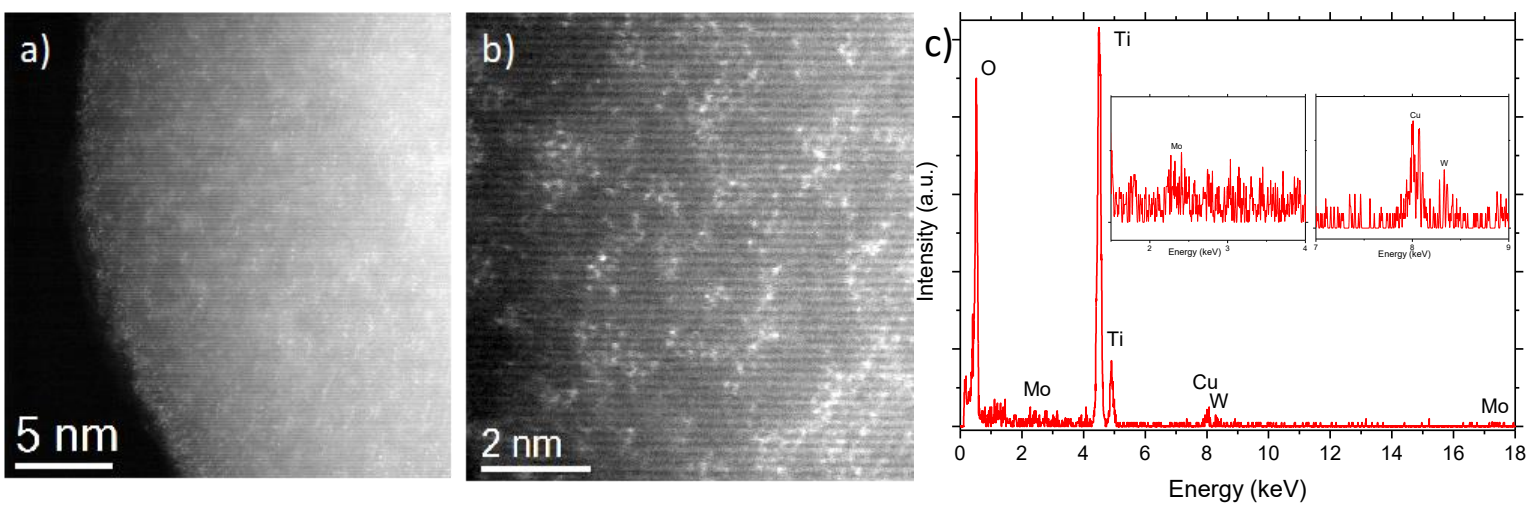

Figure 4. $\mathrm{C}_{\mathrm{s}}$-corrected STEM analysis, a) low-magnification image of a single crystal particle. b) Atomic-resolution micrograph where bright spots correspond to isolated atoms. c) EDS analysis carried out in the particle observing that it is composed by $\mathrm{Ti}$ and $\mathrm{O}$ loaded with Mo and $\mathrm{W}$ in small quantities. 


\subsection{Chemical Characterization of Nano-titanium(IV)tungstomolybdate Cation Exchanger}

\subsubsection{Ion exchange capacity (IEC)}

The cation exchange capacity of nanotitanium(IV) tungstomolybdate for $\mathrm{Na}^{+}$was done by batch equilibrium method under optimized conditions: $[\mathrm{NaCl}]=1.0 \mathrm{M}$; agitation speed $=100 \mathrm{rpm}$; contact time $=12 \mathrm{~h}$ (Figure S2-S4). The highest IEC observed was $2.41 \mathrm{meq} \cdot \mathrm{g}^{-1}$ for $\mathrm{Na}^{+}$ions for the sample calcined at $600^{\circ} \mathrm{C}$, BK-4. Lowest IEC (1.23 meq.g $\left.\mathrm{g}^{-1}\right)$ was obtained for the uncalcined sample (BK-1). The ion exchange capacity of the assynthesized material is found to be reasonably well compared with other ternary component inorganic ion exchangers from literature reports (Table 3)

\subsection{2. pH titration curve}

The $\mathrm{pH}$ titration curve was obtained under equilibrium conditions for $0.1 \mathrm{M} \mathrm{NaCl}-\mathrm{NaOH}$ system . Figure 5 indicates that nanotitanium(IV) tungstomolybdate appears to be strong cation exchanger as indicated by a low $\mathrm{pH}(\sim 2.77)$ of the solution when no $\mathrm{OH}^{-}$ion was added. As the volume of $\mathrm{NaOH}$ added to the system is increased, more $\mathrm{OH}^{-}$ions are consumed suggesting in the increase of the rate of ion exchange in basic medium due to the removal of $\mathrm{H}^{+}$ions from the external solution. The $\mathrm{pH}$ titration curve, depicted in Figure 5, showed two inflections at $\mathrm{pH} 4.9$ and 9.3, respectively, indicating that nanotitanium(IV)tungstomolybdate behaves as bifunctional ion exchanger. Thus, it exhibits two plateaus corresponding to the replacement of two hydrogen ions per mole of nanotitanium(IV) tungstomolybdate. 
Table 3 Literature comparison between Ti(IV)tungstomolybdate and other ternary component ion exchangers for $\mathrm{Na}^{+}$ions

S.No. Ion-exchanger Crystallinity IEC(meq g $\left.\mathrm{g}^{-1}\right)$ Reference No.

1. $\mathrm{Ce}(\mathrm{IV})$ iodotungstate $\quad$ Amorphous 2.86

2. $\mathrm{Sn}(\mathrm{IV})$ tungstoselenate $\quad$ crystalline $\quad 1.43$

3. $\quad \mathrm{Sn}(\mathrm{IV})$ vanadopyrophosphate Microcrystalline $\quad 3.17$

4. $\quad \mathrm{Sn}(\mathrm{IV})$ molybdosilicate $\quad$ Amorphous $\quad 0.65$

5. $\mathrm{Sn}(\mathrm{IV})$ vanadophosphate Amorphous 1.98

6. $\mathrm{Sn}(\mathrm{IV})$ arsenophosphate $\quad$ Amorphous $\quad 1.75$

7. Sn(IV)tungstoarsenate Amorphous $\quad 1.18$

8. Ti(IV)tungstosilicate $\quad$ Amorphous $\quad 0.44$

9. Ti(IV)tungstophosphate Amorphous $\quad 0.80$

10. Ti(IV)molybdosilicate Amorphous $\quad 0.74$

11. Ti(IV)iodovanadate

Amorphous $\quad 1.70$

12. $\mathrm{Zr}(\mathrm{IV})$ antimonotungstate

Amorphous

5.87

13. $\mathrm{Zr}$ (IV)tungstomolybdate Amorphous $\quad 2.40$

14. $\quad \mathrm{Zr}(\mathrm{IV})$ iodotungstate

Amorphous

0.63

15. $\mathrm{Zr}(\mathrm{IV})$ molybdopyrophosphate Amorphous 0.96-1.21

16. $\operatorname{Zr}(\mathrm{IV})$ selenomolybdate $\quad$ Amorphous $\quad 0.74$

17. $\mathrm{Zr}(\mathrm{IV})$ tungstophosphate Amorphous $\quad 1.00$

18. $\mathrm{Zr}(\mathrm{IV})$ tungstovanadate $\quad$ Amorphous $\quad 2.50$

19. $\mathrm{Zr}(\mathrm{IV})$ vanadophosphate Amorphous 1.75

20. Ti(IV)tungstomolybdate $\quad$ Crystalline $\quad 2.41$

Present work 


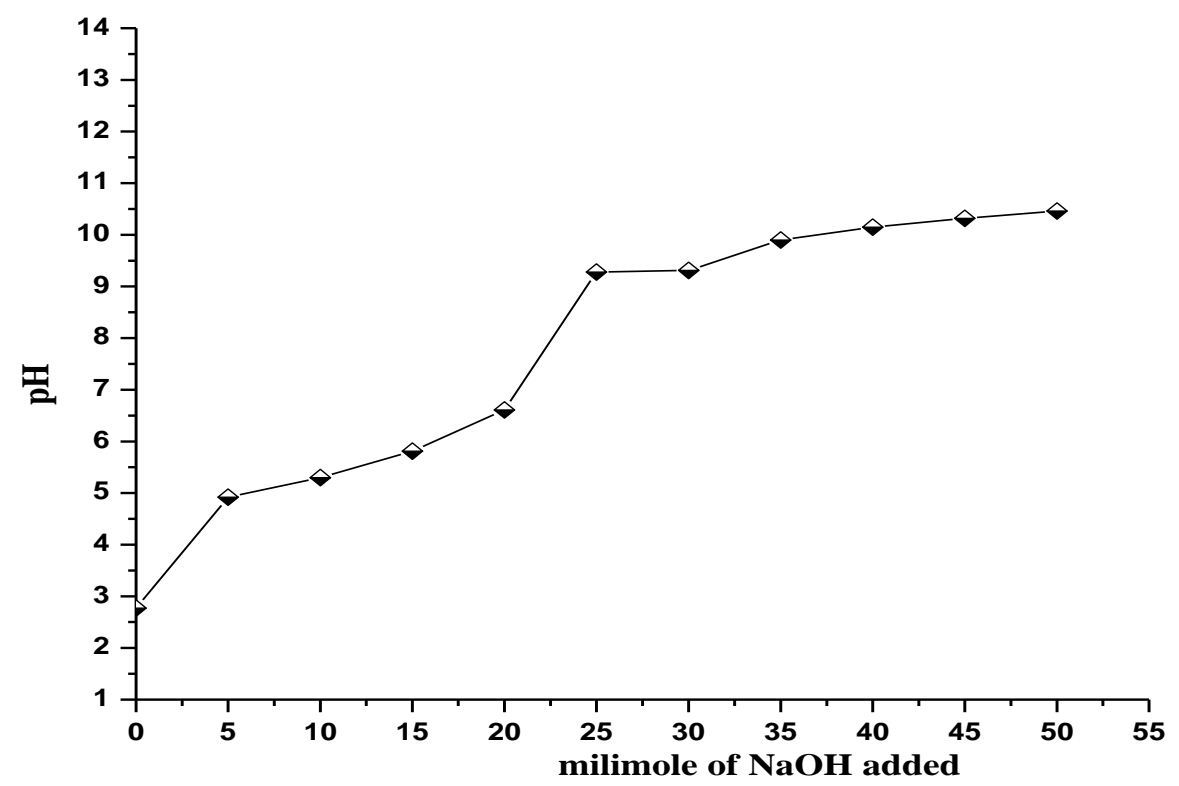

Figure 5. The pH-titration curve of nanotitanium(IV) tungstomolybdate with $0.1 \mathrm{M} \mathrm{NaOH}$.

\subsubsection{Chemical stability}

Chemical stability of an ion exchanger in acid, base and organic media is important for its applications in varied environments. The synthesized nanotitanium(IV) tungstomolybdate cation exchanger exhibits fair chemical stability in strong acids like $\mathrm{HCl}, \mathrm{HNO}_{3}, \mathrm{H}_{2} \mathrm{SO}_{4}$ up to $2 \mathrm{M}$ and also in some organic solvents up to $2 \mathrm{M}$ concentration (Table 4). However, it shows low stability in strong base media, $\mathrm{NaOH}$. This is due to the hydrolysis of the exchange materials at higher $\mathrm{pH}$ [36]. In the studied solvents, the cation exchanger's stability as well as IEC decreased with increase in the concentration of the solvent. 
Table 4: Chemical stability of Nanotitanium(IV) tungstomolybdate in different solvents ( $0.5 \mathrm{~g}$ of the exchanger was initially taken for the treatment)

\begin{tabular}{|c|c|c|c|}
\hline Solution & $\begin{array}{l}\text { Wt. After treatment } \\
(\mathrm{g})\end{array}$ & $\%$ retention & $\begin{array}{c}\text { IEC }\left(\text { meq. } \mathrm{g}^{-1}\right) \text { of retained } \\
\text { exchanger }\end{array}$ \\
\hline $0.5 \mathrm{M} \mathrm{HCl}$ & 0.361 & 72.24 & $0.52 \pm 0.04$ \\
\hline $1 \mathrm{M} \mathrm{HCl}$ & 0.345 & 69.00 & $0.40 \pm 0.01$ \\
\hline $1.5 \mathrm{M} \mathrm{HCl}$ & 0.336 & 67.20 & $0.28 \pm 0.13$ \\
\hline $2 \mathrm{M} \mathrm{HCl}$ & 0.330 & 65.90 & $0.24 \pm 0.10$ \\
\hline $0.5 \mathrm{M} \mathrm{H}_{2} \mathrm{SO}_{4}$ & 0.366 & 73.28 & $0.66 \pm 0.01$ \\
\hline $1 \mathrm{M} \mathrm{H}_{2} \mathrm{SO}_{4}$ & 0.364 & 72.70 & $0.42 \pm 0.03$ \\
\hline $2 \mathrm{M} \mathrm{H}_{2} \mathrm{SO}_{4}$ & 0.320 & 64.08 & $0.24 \pm 0.01$ \\
\hline $0.5 \mathrm{M} \mathrm{HNO}_{3}$ & 0.338 & 67.64 & $0.64 \pm 0.01$ \\
\hline $1 \mathrm{M} \mathrm{HNO}_{3}$ & 0.316 & 63.26 & $0.26 \pm 0.10$ \\
\hline $2 \mathrm{M} \mathrm{HNO}_{3}$ & 0.305 & 60.94 & $0.20 \pm 0.04$ \\
\hline $0.5 \mathrm{M} \mathrm{NaOH}$ & 0.148 & 29.50 & $0.28 \pm 0.03$ \\
\hline $1 \mathrm{M} \mathrm{NaOH}$ & 0.144 & 28.68 & $0.08 \pm 0.01$ \\
\hline $2 \mathrm{M} \mathrm{NaOH}$ & 0.063 & 12.56 & $0.02 \pm 0.01$ \\
\hline $10 \%$ Acetone & 0.325 & 65.00 & $0.58 \pm 0.11$ \\
\hline $20 \%$ Acetone & 0.245 & 48.90 & $0.08 \pm 0.01$ \\
\hline $10 \%$ Ethanol & 0.450 & 89.90 & $0.26 \pm 0.06$ \\
\hline $10 \%$ DMSO & 0.309 & 61.86 & $0.28 \pm 0.01$ \\
\hline DMW & 0.384 & 76.72 & $0.20 \pm 0.17$ \\
\hline
\end{tabular}

Direct literature comparison of our work with previous reports was not possible as many of the reports made so far in this connection focused on the amount of ions (anions, cations) released per gram of the exchanger for the solvent under consideration rather than the IEC of the exchanger after treatment in a given solvent media. Elkady et. al., reported in a way we depicted our results for an exchanger nanozirconium(IV)tungstovanadate [42] . This exchanger was reported to exhibit very well stability in both acids and organic solvents but relatively lower resistance to bases. Moreover, a decreased in stability was also observed with increased concentration of the acids considered similar to our findings.

\subsubsection{Thermal stability}

Upon heating the selected sample (BK-4) of nanotitanium(IV) tungstomolybdate, from $100^{\circ} \mathrm{C}$ to $800^{\circ} \mathrm{C}$ for $1 \mathrm{~h}$, the color of the exchanger was converted from yellow to deep yellow. The exchanger exhibited considerable thermal stability up to $500^{\circ} \mathrm{C}$ and reasonable 
stability up to $700^{\circ} \mathrm{C}$. However, the loss in mass and IEC of the exchanger was found to decrease with increasing temperature though the degree in loss of the IEC was much pronounced as compared to the loss in mass (Table 5). For example, the loss in mass for the exchanger material up to $500^{\circ} \mathrm{C}$ was only about $10 \%$ where as the loss in IEC at this temperature was found to be nearly $70 \%$. This is contrary to one might expect for crystalline nanoexchangers such as Ti(IV)tungstomolybdate since such materials are presumed to maintain their structural water much better than amorphous ones. Similar reports in this regard have been made by Abd El- Latif and Elkaday for nano zirconium vanadate the loss of which ranged from 30- 50\% depending on the synthesis approach [19]. Contrary to our findings, Nabi et al., reported more than $80 \%$ IEC retention for $\mathrm{Zr}(\mathrm{IV})$ tungstomolybdate exchanger for a temperature upto $1000^{\circ} \mathrm{C}$ [5]. In fact an increase in IEC was also registered with increase in temperature for $\mathrm{Sn}(\mathrm{IV})$ molybdosilicate ion exchanger contrary to the general observation of loss in IEC with elevated temperature [35].

Table 5: Thermal stability of nanotitanium(IV) tungstomolybdate $(0.5 \mathrm{~g}$ of the exchanger was initially taken for the treatment)

\begin{tabular}{ccccc}
\hline $\begin{array}{l}\text { Temp } \\
\left({ }^{\circ} \mathrm{C}\right)\end{array}$ & $\begin{array}{c}\text { WAH } \\
(\mathrm{g})\end{array}$ & $\begin{array}{c}\text { Mass of } \\
\text { Exchanger } \\
\text { Remaining } \\
(\%)\end{array}$ & AAH & $\begin{array}{c}\text { IEC } \\
\left(\mathrm{meq} \cdot \mathrm{g}^{-1}\right)\end{array}$ \\
\hline 100 & 0.50 & 100 & yellow & 1.50 \\
200 & 0.50 & 100 & yellow & 1.08 \\
300 & 0.49 & 98 & yellow & 0.80 \\
400 & 0.48 & 96 & yellow & 0.74 \\
500 & 0.45 & 90 & Deep yellow & 0.64 \\
600 & 0.36 & 72 & Deep yellow & 0.36 \\
700 & 0.33 & 66 & Deep yellow & 0.08 \\
800 & 0.25 & 50 & Deep yellow & - \\
\hline
\end{tabular}

WAH- Weight after heating, LIW- Loss in weight, AAH- Appearance after heating

\subsubsection{Ion exchange capacity (IEC) for metal ions}

The IEC of nanotitanium (IV) tungstomolybdate for some alkali and alkaline earth metal ions are presented in Table 6. The IEC for alkali metal ions is found to be higher than for alkaline earth metal ions. The ion exchange capacities are in the order: $\mathrm{K}^{+}>\mathrm{Na}^{+}>\mathrm{Li}^{+}$for 
alkali metals and $\mathrm{Ba}^{2+}>\mathrm{Ca}^{2+}>\mathrm{Mg}^{2+}$ for alkaline earth metals. Attraction between anions and cations in ionic crystals, obeys Coulomb's law which demands that for cations of equal charge a smaller cation will be attracted with a greater force by its counterpart anion and, therefore, will be held more tightly than a larger cation [27, 43]. Also, the extent of ionic hydration and the hydrated ionic size are inversely proportional to the atomic radius of the metal ion. IEC increases with the decrease in hydrated ionic radii down the group; thus, ions with smaller hydrated radii easily enter the pores of the exchanger resulting in higher IEC.

Table 6: IEC of nanotitanium(IV) tungstomolybdate for some alkali and alkaline earth metal ions

\begin{tabular}{llccc}
\hline Cation & Salt & Salt concentration & $\begin{array}{c}\text { Hydrated ionic } \\
\text { radii }(\AA)\end{array}$ & IEC (meq.g $\left.{ }^{-1}\right)$ \\
\hline $\mathrm{Li}^{+}$ & $\mathrm{LiCl}$ & $1 \mathrm{M}$ & 10.0 & 1.22 \\
$\mathrm{Na}^{+}$ & $\mathrm{NaCl}$ & $1 \mathrm{M}$ & 7.90 & 2.41 \\
$\mathrm{~K}^{+}$ & $\mathrm{KCl}$ & $1 \mathrm{M}$ & 5.30 & 2.49 \\
$\mathrm{Mg}^{2+}$ & $\mathrm{MgCl}_{2}$ & $1 \mathrm{M}$ & 10.80 & 0.85 \\
$\mathrm{Ca}^{2+}$ & $\mathrm{CaCl}_{2}$ & $1 \mathrm{M}$ & 9.60 & 1.12 \\
$\mathrm{Ba}^{2+}$ & $\mathrm{Ba}\left(\mathrm{NO}_{3}\right)_{2}$ & $1 \mathrm{M}$ & 8.80 & 1.13 \\
\hline
\end{tabular}

\subsubsection{Distribution studies of nanotitanium(IV) tungstomolybdate.}

The distribution coefficient, $\mathrm{K}_{\mathrm{d}}$, is the measure of the affinity of the cation exchanger towards different metal ions. The $\mathrm{K}_{\mathrm{d}}$ values of the metal ions were studied as a function of the type and concentration of the electrolyte solution and the results are presented in Table 7. It is clear from the data presented in Table 7 that $K_{d}$ values vary with the composition and nature of the solvent system. The $\mathrm{K}_{\mathrm{d}}$ values of most of metal ions in basic solvents like DMSO and DMF are higher as compared to the values in other solvent systems, especially the acidic ones. This effect can be attributed to the basic nature of these solvents, which favors the release of the hydrogen ions from the exchanger and metal ions adsorbed on it. However, on mixing $0.1 \mathrm{M}$ acetic acid in $0.1 \mathrm{M}$ DMSO and $0.1 \mathrm{M}$ formic acid in $0.1 \mathrm{M}$ $\mathrm{DMF}$, the $\mathrm{K}_{\mathrm{d}}$ value for most of the metal ions showed a significant decrease. In DMF solvent system, the $\mathrm{K}_{\mathrm{d}}$ values increased as concentration is increased from $0.05 \mathrm{M}$ to $0.1 \mathrm{M}$ 
for most of the metal ions. This trend was also observed in acidic solvent systems except for $\mathrm{Pb}^{2+}$ and $\mathrm{Cd}^{2+}$ ions.

The most promising property of the nanotitanium(IV) tungstomolybdate is its high selectivity for several hazardous heavy metal ions. For $\mathrm{Cr}^{3+}\left(\mathrm{K}_{\mathrm{d}}=11800\right), \mathrm{Pb}^{2+}\left(\mathrm{K}_{\mathrm{d}}=\right.$ 10767), $\mathrm{Hg}^{2+}\left(\mathrm{K}_{\mathrm{d}}=2521\right), \mathrm{Cd}^{2+}\left(\mathrm{K}_{\mathrm{d}}=5247\right), \mathrm{Cu}^{2+}\left(\mathrm{K}_{\mathrm{d}}=3395\right), \mathrm{Ni}^{2+}\left(\mathrm{K}_{\mathrm{d}}=6677\right)$ and $\mathrm{UO}_{2}{ }^{2+}\left(\mathrm{K}_{\mathrm{d}}=7043\right)$ in different types of solvent systems. All the values are in $\mathrm{mLg}^{-1}$. The differential behavior of the nanotitanium(IV) tungstomolybdate cation exchanger for the uptake of metal ions in different solvent systems shows that this exchanger can be effectively used for the quantitative separation of metal ions from a given mixture or from waste water.

The $K_{d}$ value of metal ions in different solvents was further demonstrated by using statistical analysis. The selectivity of metal ions in each solvent system has been compared and each metal ion was found to be significantly $(\mathrm{P}<0.05)$ selective in concerned solvent system except $\mathrm{Cd}^{2+}$ in $0.05 \mathrm{M}$ formic acid and 0.05 $\mathrm{M} \mathrm{DMF} ; \mathrm{Cu}^{2+}$ in 0.05 $\mathrm{M} \mathrm{DMF}$ and demineralized water and $\mathrm{Cr}^{3+}$ in $0.1 \mathrm{M}$ formic acid and $0.1 \mathrm{M} \mathrm{DMF}+0.1 \mathrm{M}$ formic acid (1:1) solvent systems. It can be verified from Table 7 that $\mathrm{Pb}^{2+}, \mathrm{Hg}^{2+}$ and $\mathrm{Cr}^{3+}$ are more selective in $0.05 \mathrm{M}$ formic acid than in the other solvent systems; $\mathrm{Cu}^{2+}$ and $\mathrm{UO}_{2}{ }^{2+}$ have showed the highest selectivity in 0.1 M DMSO; $\mathrm{Mn}^{2+}$ and $\mathrm{Co}^{2+}$ were found to be highly selective in $0.1 \mathrm{M}$ acetic acid; $\mathrm{Zn}^{2+}$ showed the highest selectivity in $0.3 \mathrm{M}$ formic acid; $\mathrm{Ni}^{2+}$ in $0.05 \mathrm{M} \mathrm{DMF}$ and $\mathrm{Cd}^{2+}$ in $0.1 \mathrm{M} \mathrm{DMF}$.

The distribution coefficients of metal ions were also compared with each other in the same solvent system (Table 7). From the statistical data, it can be revealed that, $\mathrm{Ni}^{2+}$ is significantly selective as compared to other metal ions in 0.05 M DMF and 0.1 DMSO + $0.1 \mathrm{M}$ acetic acid(1:1) mixed solvent; $\mathrm{Cd}^{2+}$ in $0.1 \mathrm{M} \mathrm{DMF}$ and $0.1 \mathrm{M}$ formic acid; $\mathrm{Co}^{2+}$ in 0.1 M DMF + 0.1 M formic acid (1:1) and $0.1 \mathrm{M}$ acetic acid; $\mathrm{Cr}^{3+}$ in demineralized water and in $0.05 \mathrm{M}$ formic acid; $\mathrm{UO}_{2}{ }^{2+}$ in $0.1 \mathrm{M} \mathrm{DMSO}$ and $\mathrm{Hg}^{2+}$ in $0.3 \mathrm{M}$ formic acid. From these values we can generalize that some metal ions are flexible in that they can be selectively removed from a mixture of other metal ions in various solvent systems. Hence, these metal ions can be better removed in the solvent system where they are more 
significantly selective. But it is difficult to remove one metal ion from others in a solvent showing comparable selectivity. For example, it may not be possible to remove $\mathrm{Co}^{2+}$ ion selectively from $\mathrm{UO}_{2}{ }^{2+}$ ion in $0.1 \mathrm{M}$ DMSO $+0.1 \mathrm{M}$ acetic acid (1:1) mixed solvent system.

From Table 7 it can also be observed that nanotitanium(IV) tungstomolybdate showed relatively higher distribution coefficient than the same ion exchanger in amorphous form as well as other ion exchangers for most of the metal ions. For instance, the $\mathrm{K}_{\mathrm{d}}$ value for $\mathrm{Pb}^{2+}$ (4600) and $\mathrm{Ni}^{2+}(2455)$ in $0.1 \mathrm{M}$ DMF; the $\mathrm{K}_{\mathrm{d}}$ value for $\mathrm{Cr}^{3+}$ (6278) and $\mathrm{Zn}^{2+}$ (1814) in demineralized water; the $\mathrm{K}_{\mathrm{d}}$ value for $\mathrm{Cd}^{2+}$ (5247) in $0.1 \mathrm{M}$ DMF have relatively higher distribution coefficient than others. The amorphous form of titanium(IV) tungstomolybdate (Fisseha, 2010) has the highest $\mathrm{K}_{\mathrm{d}}$ value of 1604 for $\mathrm{Pb}^{2+}, 404$ for $\mathrm{Ni}^{2+}$ and 525 for $\mathrm{Cd}^{2+}$ even in 1.0 M DMF; 4428 for $\mathrm{Cr}^{3+}$ and 933 for $\mathrm{Zn}^{2+}$ in demineralized water. The $\mathrm{K}_{\mathrm{d}}$ values for $\mathrm{Zn}^{2+}$ are 20 for zirconium(IV) arsenate and zirconium(IV) iodotungstate [ 6,24] and 187 for zirconium titanium phosphate [11] in demineralized water. All the values of $\mathrm{K}_{\mathrm{d}}$ are given in $\mathrm{mL} \cdot \mathrm{g}^{-1}$.

Another most promising feature of nanotitanium(IV) tungstomolybdate inorganic cation exchanger is its high selectivity observed for $\mathrm{UO}_{2}{ }^{2+}$ - the radio nucleotide. The exchanger exhibited considerably large distribution coefficients in most of the solvent systems. For instance, some $\mathrm{K}_{\mathrm{d}}$ values of the exchanger obtained for $\mathrm{UO}_{2}{ }^{2+}$ are 7043 in $0.1 \mathrm{M}$ DMSO, 3110 in $0.1 \mathrm{M}$ DMF, 1873 in $0.05 \mathrm{M}$ DMF 1424 in demineralized water, 1328 in $0.3 \mathrm{M}$ formic acid and 1271 in $0.1 \mathrm{M}$ formic acid. These $\mathrm{K}_{\mathrm{d}}$ values at different solvent systems reveal that nanotitanium(IV) tungstomolybdate inorganic cation exchanger can be applied for the treatment of radioactive effluents comprising uranyl ion. 
Table 7. Distribution coefficient (Kd) values of different metal ions on nanotitanium(IV) tungstomolybdate in different solvent systems

\begin{tabular}{|c|c|c|c|c|c|}
\hline $\begin{array}{l}\text { Metal } \\
\text { ion } \\
\end{array}$ & $0.1 \mathrm{M}$ DMSO & $0.1 \mathrm{M}$ Acetic acid & 0.05 M Formic acid & $0.1 \mathrm{M}$ Formic acid & $0.3 \mathrm{M}$ Formic acid \\
\hline $\mathrm{Pb}^{2+}$ & $3556^{\mathrm{d}, \mathrm{c}^{*}} \pm 0.05$ & $77^{\mathrm{m}, \mathrm{n}^{*}} \pm 0.05$ & $10767^{\mathrm{a}, b^{*}} \pm 0.01$ & $353^{\mathrm{i}, \mathrm{k}^{*}} \pm 0.01$ & $171^{\mathrm{k}, \mathrm{k}^{*}} \pm 0.01$ \\
\hline $\mathrm{Hg}^{2+}$ & $67^{\mathrm{k}, 1^{*}} \pm 0.01$ & $1467^{\mathrm{e}, \mathrm{g}^{*}} \pm 0.01$ & $2521^{\mathrm{a}, \mathrm{e}^{*}} \pm 0.00$ & $2407^{\mathrm{c}, \mathrm{c}^{*}} \pm 0.04$ & $2463^{\mathrm{b}, \mathrm{a}^{*}} \pm 0.03$ \\
\hline $\mathrm{Zn}^{2+}$ & $140^{\mathrm{i}, \mathrm{k}^{*}} \pm 0.00$ & $1244^{\mathrm{d}, \mathrm{h}^{*}} \pm 0.04$ & $383^{\mathrm{g}, \mathrm{k}^{*}} \pm 0.01$ & $874^{\mathrm{e}, \mathrm{g}^{*}} \pm 0.00$ & $2267^{\mathrm{a}, \mathrm{b}^{*}} \pm 0.07$ \\
\hline $\mathrm{Mn}^{2+}$ & $244^{\mathrm{k}, j^{*}} \pm 0.04$ & $8333^{\mathrm{a}, \mathrm{c}^{*}} \pm 0.03$ & $1022^{\mathrm{g}, \mathrm{g}^{*}} \pm 0.02$ & $1300^{\mathrm{f}, \mathrm{e}^{*}} \pm 0.00$ & $1732^{\mathrm{d}, \mathrm{d}^{*}} \pm 0.02$ \\
\hline $\mathrm{Cu}^{2+}$ & $3395^{\mathrm{a}, \mathrm{d}^{*}} \pm 0.01$ & $954^{\mathrm{g}, \mathrm{i}^{*}} \pm 0.00$ & $1374^{\mathrm{f}, \mathrm{f}^{*}} \pm 0.01$ & $2093^{\mathrm{d}, \mathrm{d}^{*}} \pm 0.00$ & $2201^{\mathrm{c}, \mathrm{c}^{*}} \pm 0.03$ \\
\hline $\mathrm{Co}^{2+}$ & $717^{\mathrm{e}, \mathrm{h}^{*}} \pm 0.03$ & $12368^{\mathrm{a}, \mathrm{a}^{*}} \pm 0.05$ & $35^{\mathrm{j}, \mathrm{n}^{*}} \pm 0.01$ & $702^{\mathrm{f}, \mathrm{i}^{*}} \pm 0.01$ & $828^{\mathrm{d}, \mathrm{h} *} \pm 0.01$ \\
\hline $\mathrm{Cr}^{3+}$ & $333^{\mathrm{i}, \mathrm{i}^{*}} \pm 0.03$ & $4000^{\mathrm{f}, \mathrm{e}^{*}} \pm 0.00$ & $11800^{\mathrm{a}, \mathrm{a}^{*}} \pm 0.00$ & $78^{\mathrm{k}, \mathrm{m}^{*}} \pm 0.01$ & $60^{1,1^{*}} \pm 0.00$ \\
\hline $\mathrm{Cd}^{2+}$ & $1800^{\mathrm{d}, \mathrm{e}^{*}} \pm 0.00$ & $172^{\mathrm{h}, \mathrm{k}^{*}} \pm 0.01$ & $227^{\mathrm{g}, 1^{*}} \pm 0.01$ & $4617^{\mathrm{b}, \mathrm{a}^{*}} \pm 0.01$ & $1700^{\mathrm{e}, \mathrm{e}^{*}} \pm 0.00$ \\
\hline $\mathrm{UO}_{2}{ }^{2+}$ & $7043^{\mathrm{a}, \mathrm{a}^{*}} \pm 0.01$ & $165^{\mathrm{j}, 1^{*}} \pm 0.01$ & $960^{\mathrm{h}, \mathrm{h}^{*}} \pm 0.01$ & $1271^{\mathrm{g}, \mathrm{f}^{*}} \pm 0.02$ & $1328^{\mathrm{f}, \mathrm{f}^{*}} \pm 0.01$ \\
\hline $\mathrm{Ni}^{2+}$ & $1520^{\mathrm{d}, \mathrm{f}^{*}} \pm 0.00$ & $118^{\mathrm{j}, \mathrm{m}^{*}} \pm 0.01$ & $470^{\mathrm{i}, \mathrm{j}^{*}} \pm 0.05$ & $728^{\mathrm{h}, \mathrm{h} *} \pm 0.03$ & $957^{\mathrm{g}, \mathrm{g}^{*}} \pm 0.01$ \\
\hline
\end{tabular}


Table 7 Continued...

\begin{tabular}{|c|c|c|c|c|c|}
\hline Metal ion & $0.05 \mathrm{M}$ DMF & $0.1 \mathrm{M} \mathrm{DMF}$ & $\begin{array}{l}0.1 \text { M DMSO + } 0.1 \\
\text { M Acetic acid }(1: 1)\end{array}$ & $\begin{array}{l}0.1 \mathrm{M} \mathrm{DMF}+0.1 \mathrm{M} \\
\text { Formic } \operatorname{acid}(1: 1)\end{array}$ & Demineralized water \\
\hline $\mathrm{Pb}^{2+}$ & $1933^{\mathrm{f}, \mathrm{c}^{*}} \pm 0.03$ & $4600^{\mathrm{c}, b^{*}} \pm 0.00$ & $125^{1, g^{*}} \pm 0.00$ & $187^{\mathrm{j}, \mathrm{f}^{*}} \pm 0.00$ & $1328^{\mathrm{g}, \mathrm{e}^{*}} \pm 0.03$ \\
\hline $\mathrm{Hg}^{2+}$ & $252^{\mathrm{i}, \mathrm{h}^{*}} \pm 0.05$ & $409^{\mathrm{g}, \mathrm{h}^{*}} \pm 0.01$ & $65^{1, \mathrm{~h}^{*}} \pm 0.00$ & $298^{\mathrm{h}, \mathrm{e}^{*}} \pm 0.01$ & $112^{\mathrm{j}, \mathrm{h}^{*}} \pm 0.00$ \\
\hline $\mathrm{Zn}^{2+}$ & $237^{\mathrm{h}, \mathrm{i}^{*}} \pm 0.00$ & $633^{\mathrm{f}, \mathrm{g}^{*}} \pm 0.03$ & $70^{\mathrm{j}, \mathrm{h}^{*}} \pm 0.03$ & $48^{\mathrm{k}, \mathrm{k}^{*}} \pm 0.00$ & $1814^{\mathrm{b}, \mathrm{c}^{*}} \pm 0.01$ \\
\hline $\mathrm{Mn}^{2+}$ & $1511^{\mathrm{e}, \mathrm{e}^{*}} \pm 0.01$ & $84^{\mathrm{m}, 1^{*}} \pm 0.01$ & $388^{\mathrm{j}, \mathrm{e}^{*}} \pm 0.01$ & $158^{1, \mathrm{~g}^{*}} \pm 0.02$ & $921^{\mathrm{h}, \mathrm{f}^{*}} \pm 0.04$ \\
\hline $\mathrm{Cu}^{2+}$ & $35^{1, m^{*}} \pm 0.00$ & $233^{\mathrm{j}, \mathrm{i}^{*}} \pm 0.04$ & $383^{\mathrm{i}, \mathrm{f}^{*}} \pm 0.00$ & $418^{\mathrm{h}, \mathrm{d}^{*}} \pm 0.01$ & $34^{1, j^{*}} \pm 0.03$ \\
\hline $\mathrm{Co}^{2+}$ & $28^{\mathrm{k}, 1^{*}} \pm 0.01$ & $105^{\mathrm{h}, \mathrm{k}^{*}} \pm 0.00$ & $5^{\mathrm{m}, \mathrm{k}^{*}} \pm 0.00$ & $1229^{\mathrm{c}, \mathrm{a}^{*}} \pm 0.05$ & $17^{1, \mathrm{k}^{*}} \pm 0.00$ \\
\hline $\mathrm{Cr}^{3+}$ & $533^{\mathrm{h}, \mathrm{g}^{*}} \pm 0.03$ & $156^{\mathrm{j}, j^{*}} \pm 0.06$ & $533^{\mathrm{h}, \mathrm{d}^{*}} \pm 0.03$ & $78^{\mathrm{k}, \mathrm{i}^{*}} \pm 0.04$ & $6278^{\mathrm{c}, \mathrm{a}^{*}} \pm 0.02$ \\
\hline $\mathrm{Cd}^{2+}$ & $230^{\mathrm{g}, \mathrm{j}^{*}} \pm 0.00$ & $5247^{\mathrm{a}, \mathrm{a}^{*}} \pm 0.01$ & $15^{\mathrm{k}, \mathrm{j}^{*}} \pm 0.01$ & $63^{\mathrm{j}, \mathrm{j}^{*}} \pm 0.05$ & $472^{\mathrm{f}, \mathrm{g}^{*}} \pm 0.02$ \\
\hline $\mathrm{UO}_{2}{ }^{2+}$ & $1873^{\mathrm{d}, \mathrm{d}^{*}} \pm 0.03$ & $3010^{\mathrm{c}, \mathrm{d}^{*}} \pm 0.01$ & $2^{\mathrm{n}, \mathrm{k}^{*}} \pm 0.05$ & $28^{1,1^{*}} \pm 0.04$ & $1424^{\mathrm{e}, \mathrm{d}^{*}} \pm 0.01$ \\
\hline $\mathrm{Ni}^{2+}$ & $6677^{\mathrm{a}, \mathrm{a}^{*}} \pm 0.01$ & $2455^{\mathrm{c}, \mathrm{e}^{*}} \pm 0.04$ & $1017^{\mathrm{f}, \mathrm{a}^{*}} \pm 0.01$ & $1162^{\mathrm{e}, \mathrm{b}^{*}} \pm 0.03$ & $106^{\mathrm{k}, \mathrm{i}^{*}} \pm 0.01$ \\
\hline
\end{tabular}

- The values for the distribution coefficient of each metal ion are the average of the three replicate measurements

- $\quad \mathrm{a}, \mathrm{b}, \mathrm{c}, \mathrm{d}, \mathrm{e}, \mathrm{f}, \mathrm{g}, \mathrm{h}, \mathrm{i}, \mathrm{j}, \mathrm{k}=$ (means in the same row with same letter are not significantly different at $\mathrm{P}=0.05$ )

- $a^{*}, b^{*}, c^{*}, d^{*}, e^{*}, f^{*}, g^{*}, h^{*}=$ (means in the same column with same letter are not significantly different at $P=0.05$ )

- Letters having * sign were used to compare the $\mathrm{K}_{\mathrm{d}}$ values of metal ions in each solvent system i.e. down the column 


\section{Conclusion}

In this study, an inorganic cation exchanger, nanotitanium(IV)tungstomolybdate was synthesized, characterized and evaluated for its cation exchange capacity (IEC) and other properties. The IEC for $\mathrm{Na}^{+}$ions for this exchanger was found to be $2.41 \mathrm{meqg}^{-1}$ for the material calcined at $600^{\circ} \mathrm{C}$. Nanotitanium(IV) tungstomolybdate obtained as yellow powder was found to be stable in water, fairly well stable in strong acids like $\mathrm{HCl}, \mathrm{HNO}_{3}, \mathrm{H}_{2} \mathrm{SO}_{4}$ up to $2 \mathrm{M}$ and in some organic solvents but it exhibited a lower stability in strong base $\mathrm{NaOH}$ (only $12 \%$ retained in $2 \mathrm{M} \mathrm{NaOH}$ ). For the studied solvents, the chemical stability as well as IEC of the retained exchanger decreased with the increase in concentration of solvent. The study of the thermal effect on ion exchange capacity of the material shows stability up to $500^{\circ} \mathrm{C}$. The ion exchange capacity decreases with the increase in temperature. The $\mathrm{pH}$ titration curve obtained under equilibrium conditions for $\mathrm{NaCl}-\mathrm{NaOH}$ system revealed that nanotitanium(IV) tungstomolybdate has bifunctional nature and strong acidic cation exchange. Another important property of the above cation exchanger is its selectivity to different types of toxic heavy metal ions. The distribution coefficient of heavy toxic metal ions was studied in water and different solvent systems at various concentrations. The $\mathrm{pH}$ of the solvent has considerable effect on the affinity of these metal ions towards the ion exchanger. Very high distribution coefficient values for $\mathrm{Pb}^{2+}$ $\left(\mathrm{K}_{\mathrm{d}}=10767 \mathrm{~mL} \cdot \mathrm{g}^{-1}\right)$ and $\mathrm{Cr}^{3+}\left(\mathrm{K}_{\mathrm{d}}=11800 \mathrm{~mL} \cdot \mathrm{g}^{-1}\right)$ ions indicate that the exchanger can be used to selectively adsorb $\mathrm{Pb}^{2+}$ and $\mathrm{Cr}^{3+}$ ions from the waste containing other metal ions. The exchanger also exhibited considerably high affinity towards uranyl $\left(\mathrm{K}_{\mathrm{d}}=7043\right.$ in $0.1 \mathrm{M} \mathrm{DMSO}$ for $\mathrm{UO}_{2}{ }^{2+}$ ) which reveals that the nanotitanium(IV) tungstomolybdate can be applied for treatment of radioactive waste treatment.

\section{Acknowledgements}

ID is grateful to CSIC for her research leave at AAU and HU. The financial support from the Spanish Government MINECO (project MAT2012-31127), CSIC for Development (project COOPB20082), the Research and Extension Office of Haramaya University, the School of Graduate Studies and Chemistry Department of HU are acknowledged. 


\section{References}

[1] Akieh, M.N., M, Lahtinen, A. Väisänen and M. Sillan, 2008. Preparation and characterization of sodium iron titanate ion exchanger and its application in heavy metal removal from waste waters. Journal of Hazardous Materials. 152: 640-647

[2] Fenglian Fu, Qi Wang Removal of heavy metal ions from wastewaters: A review Journal of Environmental Management 92 (2011) 407-418

[3] Lin, S. and R. Juang, 2002. Heavy metal removal from water by sorption using surfactantmodified montmorillonite. Journal of Hazardous Materials 92B: 315-326.

[4] Kantipuly, C.J. and A. D. Westland, 1988. Review of methods for the determination of lanthanides in geological samples. Talanta. 35: 1-13.

[5] Nabi, S.A., A. H. Shalla, A. M. Khan, S. A. Ganie, 2007b. Synthesis, characterization and analytical applications of titanium(IV) molybdosilicate: A cation ion-exchanger. Journal of colloids and surfaces A, 302: 241- 250.

[6] Nabi, S., A. Alimuddin and I. Aminual, 2009. Synthesis and characterization of a new cation exchanger-zirconium(IV)iodotungstate: Separation and determination of metal ion contents of synthetic mixtures, pharmaceutical preparations and standard reference material. $J$. of Hazardous Materials. 172(1) 202-207.

[7] Ferreira, T. R., C. B. Lopes, P. F. Lito, M. Otero, Z. Lin, J. Rocha, E. Pereira, C. M. Silva, A. Duarte, 2009. Cadmium (II) removal from aqueous solution using microporous titanosilicate ETS-4. Chemical Engineering Journal, 147: 173-179.

[8] Clearfield, A., A. I. Bortuna, S. A. Khainakova, L. N. Bortuna, V. V. Strelko and V. N. Khryaschevskii,1998. Spherically granulated titanium phosphate as exchanger for toxic heavy metals. Waste Management. 18: 203-210.

[9] Yoshitaka G. and E.O. da silva, 1990. Cation exchange of divalent metal ions on zirconium(IV) phosphosilicate cation exchanger. Journal of hazardous metals, 1: $84-86$.

[10] Bamlaku Semagne, Isabel Diaz, Tesfahun Kebede, Abi M. Taddesse Synthesis, characterization and analytical application of polyaniline tin(IV) molybdophosphate composite with nanocrystalline domains Reactive and Functional Polymers 98(2016) 17-23

[11] Thakkar, R. and U. Chudasama, 2009. Synthesis and characterization of zirconium titanium phosphate and its application in separation of metal ions. Journal of Hazardous Materials. 172: 129-137.

[12] F. Mohammadi Zonoz, S.J. Ahmadi, S. Attar Nosrati, M. Ghannadi Maragheh Preparation and characterization of zirconium (IV) molybdo tungsto vanado silicate as a novel inorganic ion exchanger in sorption of radionuclides Journal of Hazardous Materials 169 (2009) 808-812 
[13] R.R. Sheha, S.H. El-Khouly Adsorption and diffusion of cesium ions in zirconium(IV)iodomolybdate exchanger Chemical Engineering Research and Design 91 (2013) 942-954

[14] Pankaj Sharma, Neetu Synthesis, characterization and sorption behavior of zirconium(IV) antimonotungstate: An inorganic ion exchanger Desalination 267 (2011) 277-285

[15] Yavari, R., S.J. Ahmadi, Y.D. Huang, A.R. Khanchi, G. Bagheri, J.M. He., 2009. Synthesis, characterization and analytical application of a new cation exchanger - titanium(IV) molybdophosphate. Talanta. 77: $1179-1184$.

[16] Türker, A. R., 2007. New sorbents for solid-phase extraction for metal enrichment. Clean. 35:548-557.

[17] Lemos, V.A., L.S.G. Teixeira, M.A. Bezerra, A.C.S. Costa, J.T. Castro, L.A.M. Cardoso, D.S. Jesus, E.S. Santos, P.X. Baliza and L.N. Santos, 2008. New materials for solid-phase extraction of trace elements. Appl. Spectrosc. Rev. 43: 303-334.

[18] Zhang, L., T. Huang, M. Zhang, X. Guo and Z. Yuan, 2008. Studies on the capability and behavior of adsorption of thallium on nano- $\mathrm{Al}_{2} \mathrm{O}_{3}$. J. Hazard. Mater. 157: 352-357.

[19] Abd El-Latif, M.M. and M.F. El-kady, 2011. Synthesis, characterization and evaluation of nano-zirconium vanadiate ion exchanger by using three different techniques. Material Research bulletin. 46:105-118.

[20] Nano-cerium vanadate: A novel inorganic ion exchanger for removal of americium and uranium from simulated aqueous nuclear waste Chayan Banerjee, Nilesh Dudwadkara, Subhash Chandra Tripathi, Pritam Maniklal Gandhia, Vinita Groverb, Chetan Prakash Kaushik ,Avesh Kumar Tyagi Journal of Hazardous Materials 280 (2014) 63-70

[21] Oren, E. E., E. Taspinar and A. C. Tas, 1997. Preparation of lead zirconate by homogeneous precipitation and calcination. J. Am. Ceram. Soc. 80 (10): 2714-16.

[22] Yanhong, L., Z. Yongming, H. Guangyan, Y. Yingning, 2008. Upconversion luminescence of $\mathrm{Y}_{2} \mathrm{O}_{3}: \mathrm{Er}^{3+}, \mathrm{Yb}^{3+}$ nanoparticles prepared by a homogeneous precipitation method. Journal of Rare Earths. 26(3): 450-454.

[23] Murthy, Y.L.N., I.V.K. Viswanath, T.K.Rao and R.Singh, 2009. Synthesis and characterization of nickel copper ferrite. International Journal of Chem.Tech. Research. 1(4): $1308-1311$.

[24] Nabi, S. A. and A. H. Shalla, 2009. Synthesis, characterization and analytical application of hybrid; Acrylamide zirconium (IV) arsenate a cation exchanger, effect of dielectric constant on distribution coefficient of metal ions. Journal of Hazardous Materials. 163: 657-664. 
[25] Nabi, S.A. and M. Naushad, 2008. Synthesis, characterization and analytical applications of a new composite cation exchanger cellulose acetate- $\mathrm{Zr}(\mathrm{IV})$ molybdophosphate. Colloids and Surfaces A: Physicochem. Eng. Aspects. 316: 217-225.

[26] Chand, S., Seema, Arti and C. V. Chahal, 2011. Synthesis, characterization and ion exchange properties of a new ion exchange material: Bismuth (III) iodophosphate. Recent Research in Science and Technology. 3(6): 01-08.

[27] Nabi, S. A. and A. M. Khan, 2006. Synthesis, ion exchange properties and analytical applications of stannic silicomolybdate: Effect of temperature on distribution coefficients of metal ions. Reactive \& Functional Polymers. 66:495-508

[28] Abd El-Latif, M.M. and M.F. El-kady, 2008. Developing \& characterization of a new zirconium vanadate ion exchanger and its novel organic- inorganic hybrid. Journal of Applied Sciences Research. 4(1): 1-13.

[29] Silva, G.L.J.P, M.L.CP. Da Silva and T. Cartano, 2002. Preparation and characterization of hydrous zirconium oxide formed by homogeneous precipitation. Material Research, 5: 149-153.

[30] B. El-Gammal, S.A. Shady Chromatographic separation of sodium, cobalt, and europium on the particles of zirconium molybdate and zirconium silicate ion exchangers Colloids and Surfaces A: Physicochem. Eng. Aspects 287 (2006) 132- 138

[31] Li, W., S. I. Shah, M. Sung and C.P. Huang, 2002. Structure and size distribution of $\mathrm{TiO}_{2}$ nanoparticles deposited on stainless steel mesh. J. Vac. Sci. Technol. B. 20(6):2303-2308.

[32] Dhara, S., S. Sarkar, S. Basu, P. Chattopadhyay, 2009. Separation of the ${ }^{90} \mathrm{Sr}-{ }^{90}$ Y pair with cerium(IV) iodotungstate cation exchanger. Applied Radiation and Isotopes, 67: 530-53.

[33] Mu. Naushad Inorganic and Composite Ion Exchange Materials and their Applications Ion Exchange Letters 2(2009) 1-14: In M.G. Marageh, S.W. Hussain, A.R. Khanchi, J. Radioanal. Nucl. Chem. 241(1999) 139

[34] Mu. Naushad Inorganic and Composite Ion Exchange Materials and their Applications Ion Exchange Letters 2(2009) 1-14: In S.A. Nabi, Z.M. Siddiqi, Bull. Chem. Soc. Jpn. 58(1985) 724

[35] M Qureshi, A P Gupta, S. N A Rizviz and N A Shakeel Synthesis and ion exchange properties of thermally stable, Th(IV) selective Sn(IV)molybdosylicate: Comparison with other Sn(IV) base ion exchangers Reactive Polymers, 3 (1984) 23-31

[36] Mahmood Siddiqi, Deepak Pathania Titanium(IV) tungstosilicate and titanium(IV) tungstophosphate: two new inorganic ion exchangers Zia Journal of Chromatography A, 987 (2003) 147-158 
[37] Syed Asfaq Nabi, Mu. Naushad A new electron exchange material Ti(IV) iodovanadate: Synthesis, characterization and analytical applicationsChemical Engineering Journal158 (2010) $100-107$

[38] Syed Ashfaq Nabi, Mu. Naushad, Inamuddin Synthesis and characterization of a new inorganic cation-exchanger- $\mathrm{Zr}$ (IV)tungstomolybdate: Analytical applications for metal content determination in real sample and synthetic mixture Journal of Hazardous Materials 142 (2007) 404-411

[39] Kai Lv, Yang-Ming Luo, Liang-Ping Xiong Studies on ion exchange behavior of cesium into zirconium molybdopyrophosphate and its application as precursor of cesium ion sieve Colloids and Surfaces A: Physicochem. Eng. Aspects 417 (2013) 243- 249

[40] A.P. Gupta, G.L. Verma, Saiqa Ikram Studies on a new heteropolyacid-based inorganic ion exchanger; zirconium(IV) selenomolybdate Reactive \& Functional Polymers 43 (2000) 33-41

[41] A.P. Gupta , Pradeep K. Varshney Investigation of some kinetic parameters for $M^{*}+-$ $\mathrm{H}+$ exchanges on zirconium(IV) tungstophosphate - a cation exchanger Reactive \& Functional Polymers 32 (1997) 67-74

[42] M. F. Elkady, E. M. El-Sayed, H. A. Farag, and A. A. Zaatout Assessment of Novel Synthetized Nanozirconium Tungstovanadate as Cation Exchanger for Lead Ion Decontamination Journal of Nanomaterials Volume 2014, Article ID 149312,11 pages http://dx.doi.org/10.1155/2014/14931

[43] H.O. Gupta, H.D. Tayal Zirconium vanadophosphate as an inorganic ion exchanger Analytica Chimica Acta, 235 (1990) 435-440 